\begin{tabular}{ll|l} 
Case Reports in & \multicolumn{2}{c}{ Case Rep Gastroenterol 2019;13:238-244 } \\
\cline { 2 - 3 } Gastroenterology & $\begin{array}{l}\text { DOl: 10.1159/000499423 } 2019 \text { The Author(s) } \\
\text { Published online: May 16, } 2019\end{array}$ & $\begin{array}{l}\text { Published by S. Karger AG, Basel } \\
\text { www.karger.com/crg }\end{array}$ \\
\cline { 2 - 3 } & $\begin{array}{l}\text { This article is licensed under the Creative Commons Attribution-NonCommercial } 4.0 \\
\text { International License (CC BY-NC) (http://www.karger.com/Services/OpenAccessLicense). } \\
\text { Usage and distribution for commercial purposes requires written permission. }\end{array}$
\end{tabular}

\title{
Synchronous Resection of Colon Adenocarcinoma and Bisegmentectomy of Liver Metastases
}

\author{
Eduardo Esteban Montalvo-Javé ${ }^{a, d} \quad$ Billy Jiménez Bobadilla ${ }^{c}$ \\ Mariana Espejel Deloiza ${ }^{a} \quad$ Irving Hugo Aguilar Preciado ${ }^{a}$ \\ Luis Fernando Negrete Cervantes ${ }^{a}$ Héctor Diliz-Pérez ${ }^{b}$ \\ ${ }^{a}$ Clínica de Cirugía Hepato-Pancreato-Biliar, Servicio de Cirugía General, Hospital General \\ de México, "Dr. Eduardo Liceaga", Mexico City, Mexico; 'bervicio de Cirugía de \\ Trasplantes, Hospital General de México, "Dr. Eduardo Liceaga", Mexico City, Mexico; \\ "Servicio de Coloproctología, Hospital General de México, "Dr. Eduardo Liceaga", \\ Mexico City, Mexico; dDepartamento de Cirugía, Facultad de Medicina, UNAM, \\ Mexico City, Mexico
}

\section{Keywords}

Colon adenocarcinoma $\cdot$ Liver metastases $\cdot$ Resection

\begin{abstract}
Colorectal cancer is one of the main neoplasms worldwide; at the time of diagnosis about $25 \%$ of cases already have an advanced stage with the presence of metastases. A 58-yearold female presented with nausea, vomiting, and black stools and diffuse abdominal pain associated with $7 \%$ weight loss. She was referred to our hospital with signs of digestive tract bleeding and anemic syndrome. Panendoscopy revealed body and fundus gastropathy and presence of Helicobacter pylori, and colonoscopy showed a neoplastic lesion at the ascending colon level. A synchronous resection was performed in a single surgical time of colorectal cancer and liver metastases with a duration of $4 \mathrm{~h}$ and bleeding of $900 \mathrm{~mL}$. The oral feeding started $24 \mathrm{~h}$ after surgery, presenting gas channeling at $24 \mathrm{~h}$ and evacuations at $48 \mathrm{~h}$. The total intrahospital stay was 5 days. Synchronous resection of hepatic metastases in colorectal cancer is still rarely performed, despite the fact that in recent years the number of cases has increased because of better surgical techniques. Synchronous
\end{abstract}


resection of colorectal cancer and liver metastases can be performed safely, without increasing transoperative mortality when performed in specialized centers with a multidisciplinary team; however, it is essential to emphasize the importance of negative surgical margins (R0) of the primary tumor and later to be complemented with adjuvant treatment with chemotherapy.

\section{Introduction}

Colorectal cancer reported 136,000 new cases in 2014 and caused more than 50,000 deaths during the same year in the United States, being one of the main neoplasms worldwide, mainly in developed countries. It is estimated that at the time of diagnosis, about $25 \%$ of patients already have advanced stages, with the presence of metastases, with liver metastases being the most frequent $[1,2]$.

Colorectal cancer is a complex disease that involves various alterations at the chromosomal level which determines the response to chemotherapy, requiring individualized management in each patient $[3,4]$.

Metastases in colorectal cancer, as well as in gastrointestinal malignant neoplasms, disseminate by blood to the portal circulation; thus, the liver is the first site of invasion in colorectal cancer.

When liver metastases are greater than $2 \mathrm{~mm}$, they begin to have circulatory supply from the hepatic artery [4].

The 5-year survival rate in patients with colorectal cancer, with the presence of metastasis and without receiving treatment, is as low as 13\% in the United States [5].

Therefore, we present the following case in which synchronous resection was performed in a single surgical time for colorectal cancer and liver metastases at the "Hospital General de México."

\section{Case Report}

We report the case of a 58-year-old female with a personal history of diabetes mellitus diagnosed 8 years prior, treated with metformin and glibenclamide, a surgical history of two cesarean sections, without complications, and a family history of diabetes mellitus, arterial hypertension, and cholangiocarcinoma. She was referred to our hospital in November 2015 presenting nausea, vomiting, black stools, and diffuse and sporadic epigastric pain; she also lost $4 \mathrm{~kg}$ in 4 months, from 65 to $61 \mathrm{~kg}$, which means a total of $7 \%$ weight loss, and showed signs of digestive tract bleeding and anemic syndrome. Serological studies, prior to hospital arrival, showed hemoglobin of $8.4 \mathrm{~g} / \mathrm{dL}$.

Initial laboratory results included leukocytes $8,260 \mu / \mathrm{L}$, hemoglobin $10.56 \mathrm{~g} / \mathrm{dL}$, platelets $222,000 \mu / \mathrm{L}$, gamma glutamyl transpeptidase $22 \mu$ /L, lactate dehydrogenase $207 \mu / \mathrm{L}$, alkaline phosphatase $71 \mu / \mathrm{L}$, AST $15 \mu / \mathrm{L}$, ALT $13 \mu / \mathrm{L}$, prothrombin time $6.7 \mathrm{~s}$, serum albumin $3.5 \mathrm{~g} / \mathrm{dL}$, glucose $185 \mathrm{mg} / \mathrm{dL}$, urea $26.9 \mathrm{mg} / \mathrm{dL}$, creatinine $0.5 \mathrm{mg} / \mathrm{dL}$, and serum carcinoembryonic antigen was elevated to $114.56 \mathrm{UI}$.

The approach protocol started with panendoscopy, showing body and fundus gastropathy and presence of Helicobacter pylori. Four months later, a colonoscopy was performed which revealed a right colonic tumor. 
An abdominal CT scan followed, which revealed the following: liver with hypodense tumor, with regular edges, in segment $\mathrm{V}, 24 \times 22 \times 16 \mathrm{~mm}$, and longitudinal thickening of $82 \mathrm{~mm}$ with a reduction of $100 \%$ of the intestinal lumen (Fig. 1a). PET CT showed a nodular lesion of $25 \times 21 \mathrm{~mm}$ in segment $V$ with maximum SUV of 17.1, a poorly defined lesion in segment VI of $11 \mathrm{~mm}$ in diameter, and maximum SUV of 6; ascending colon of $45 \mathrm{~cm}^{3}$ with maximum SUV of 51.4 (Fig. 1b).

An open surgical procedure was performed in May 2016 with right hemicolectomy with ileorectal mechanical anastomosis and hepatic bisegmentectomy V and VI (Fig. 2). The duration of the surgical procedure was $4 \mathrm{~h}$, with a $6 \mathrm{~h}$ anesthetic time, and total estimated bleeding was $900 \mathrm{~mL}$. The oral feeding started $24 \mathrm{~h}$ after the procedure, presenting intestinal gas release at $24 \mathrm{~h}$ and evacuations at $48 \mathrm{~h}$. Total intrahospital stay was 5 days, presenting right axillary vein thrombosis due to placement of central venous catheter guided by interventional radiology.

The histological diagnosis was moderately differentiated adenocarcinoma, intestinal type, with cecum, ascending colon, and appendicular involvement; free surgical margins (R0), nodules 2/11; hepatic lesions with neoplastic cells (Fig. 3).

The postoperative stay was uneventful while the patient received chemotherapy with capecitabine and oxaliplatin. The patient showed carcinoembryonic antigen 3.93 UI without tumor activity by CT. ECOG was 0 and IK was 1000 during the follow-up time of 9 months.

\section{Discussion}

Synchronous resection of hepatic metastases in colorectal cancer is still rarely performed, despite the fact that in recent years the number of cases has increased because of better surgical techniques available and better training in liver surgery together with the actual unresectability criteria of hepatic metastases in colorectal cancer.

Currently there are only two contraindications to perform this procedure, summarized as: inability to perform surgical resection $\mathrm{R} 0$ and inability to maintain a liver remnant that ensures adequate physiological capacity [6].

The presence of hepatic metastases in colorectal cancer is considered clinical stage IV; survival in these patients without undergoing surgical treatment ranges from 20 to 24 months, compared with a 5-year survival in patients undergoing surgical treatment that reaches up to $58 \%$ [5].

The time and order in which surgical treatment of colorectal cancer and liver metastases should be performed is still a matter of controversy; however, different studies have shown that performing a synchronous resection, in which the resection of colorectal cancer and metastases are performed with a time difference of no more than 3 months [5], is a procedure that can be performed safely in specialized centers.

Benefits of performing a synchronous resection are the possibility of performing both resections in a single surgical time, a single major surgery, and this translates into faster recovery and the possibility of returning to daily activities in a shorter period of time, but the most important point is that it will diminish the time between surgical treatment and the start of chemotherapy, resulting in a better and faster oncological treatment.

The number of procedures of this type that are carried out worldwide is limited, since it requires a multidisciplinary team.

Therefore, we conclude, synchronous resection of colorectal cancer and liver metastases can be performed safely, without increasing operative mortality, when performed in spe- 
cialized centers with a multidisciplinary team; it is essential to emphasize the importance of negative surgical margins (R0) of the primary tumor and later to be complemented with adjuvant treatment with chemotherapy.

\section{Statement of Ethics}

The authors have no ethical conflicts to disclose. Written informed consent was obtained from the patient for publication of the present case report and any relevant images.

\section{Disclosure Statement}

The authors have no conflicts of interest to declare.

\section{Funding Sources}

There were no funding sources.

\section{Author Contributions}

Eduardo E. Montalvo-Javé: acquisition, analysis, interpretation of data for the work, revising it critically for important intellectual content, final approval of the version to be published, and agreement to be accountable for all aspects of the work in ensuring that questions related to the accuracy or integrity of any part of the work are appropriately investigated and resolved.

Billy Jiménez Bobadilla: acquisition, analysis, interpretation of data for the work and revising it critically for important intellectual content, final approval of the version to be published, and agreement to be accountable for all aspects of the work in ensuring that questions related to the accuracy or integrity of any part of the work are appropriately investigated and resolved.

Mariana Espejel Deloiza: acquisition, analysis, interpretation of data for the work and revising it critically for important intellectual content, final approval of the version to be published, and agreement to be accountable for all aspects of the work in ensuring that questions related to the accuracy or integrity of any part of the work are appropriately investigated and resolved.

Irving Hugo Aguilar Preciado: acquisition, analysis, interpretation of data for the work and revising it critically for important intellectual content, final approval of the version to be published, and agreement to be accountable for all aspects of the work in ensuring that questions related to the accuracy or integrity of any part of the work are appropriately investigated and resolved.

Luis Fernando Negrete Cervantes: acquisition, analysis, interpretation of data for the work and revising it critically for important intellectual content, final approval of the version to be published, and agreement to be accountable for all aspects of the work in ensuring that 
questions related to the accuracy or integrity of any part of the work are appropriately investigated and resolved.

Héctor Diliz-Perez: acquisition, analysis, interpretation of data for the work and revising it critically for important intellectual content, final approval of the version to be published, and agreement to be accountable for all aspects of the work in ensuring that questions related to the accuracy or integrity of any part of the work are appropriately investigated and resolved.

\section{References}

1 Castellanos JA, Merchant NB. Strategies for Managment of Synchronus Colorectal Metastases. Curr Surg Rep. 2014 Jun;2(62):1-13.

2 Silberhumer GR, Paty PB, Temple LK, Araujo RL, Denton B, Gonen M, et al. Simultaneous resection for rectal cancer with synchronous liver metastasis is a safe procedure. Am J Surg. 2015 Jun;209(6):935-42.

3 Veereman G, Robays J, Verleye L, Leroy R, Rolfo C, Van Cutsem E, et al. Pooled analysis of the surgical treatment for colorectal cancer liver metastases. Crit Rev Oncol Hematol. 2015 Apr;94(1):122-35.

4 Zarour LR, Anand S, Billingsley KG, Bisson WH, Cercek A, Clarke MF, et al. Colorectal Cancer Liver Metastasis: Evolving Paradigms and Future Directions. Cell Mol Gastroenterol Hepatol. 2017 Jan;3(2):163-73.

5 Jeong S, Heo JS, Park JY, Choi DW, Choi SH. Surgical resection of synchronous and metachronous lung and liver metastases of colorectal cancers. Ann Surg Treat Res. 2017 Feb;92(2):82-9.

6 Denstman F. An approach to the newly diagnosed colorectal cancer patient with synchronous stage 4 disease. Surg Oncol Clin N Am. 2014 Jan;23(1):151-60. 


\section{Case Reports in Gastroenterology}

\begin{tabular}{l|l}
\hline Case Rep Gastroenterol 2019;13:238-244 \\
\hline DOI: 10.1159/000499423 & $\begin{array}{l}\text { ( ) 2019 The Author(s). Published by S. Karger AG, Basel } \\
\text { www.karger.com/crg }\end{array}$ \\
\hline
\end{tabular}

Montalvo-Javé et al.: Synchronous Resection of Colon Adenocarcinoma and Bisegmentectomy of Liver Metastases

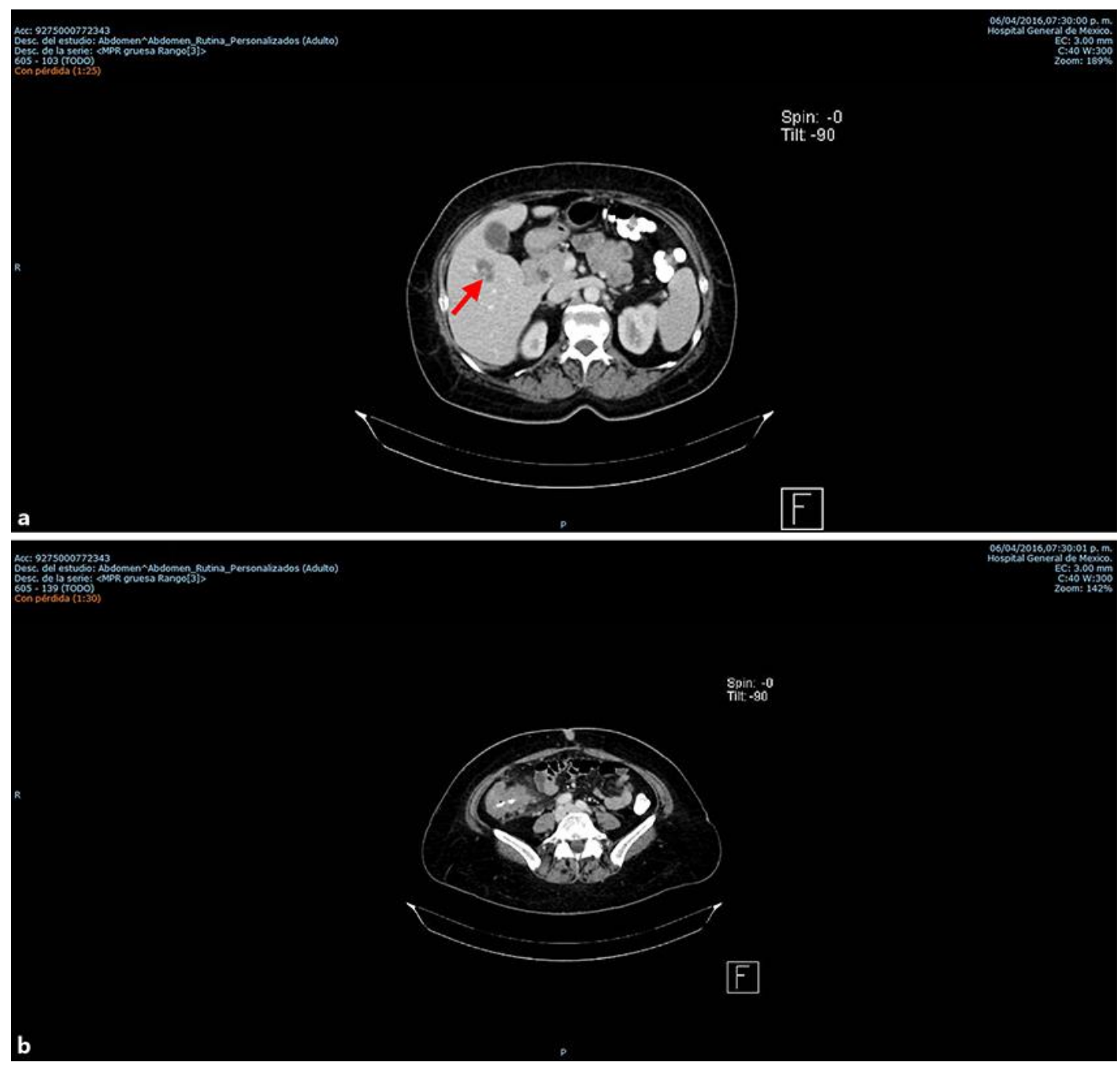

Fig. 1. a CT: Hepatic metastases (red arrow). b Colorectal cancer at the ascending colon.

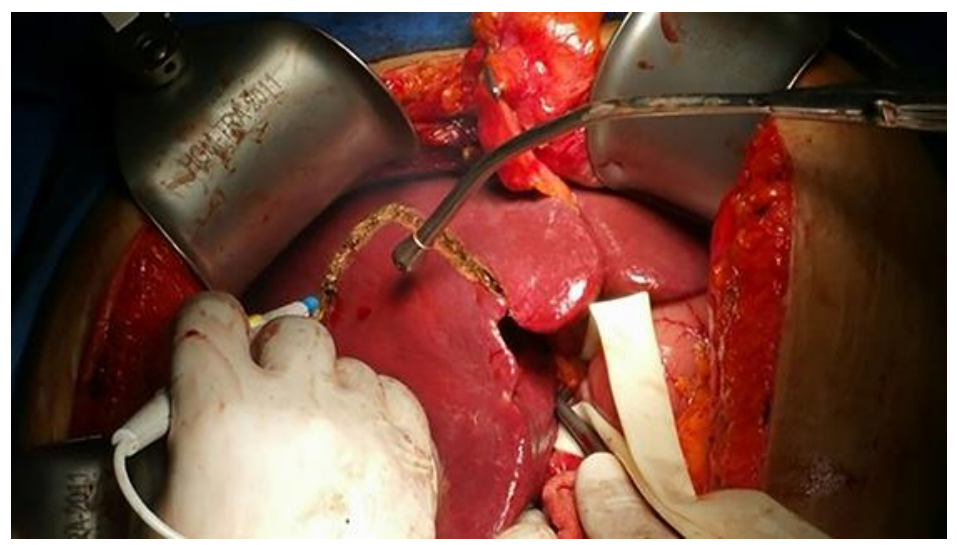

Fig. 2. Hepatic resection, segments V and VI. 
Montalvo-Javé et al.: Synchronous Resection of Colon Adenocarcinoma and Bisegmentectomy of Liver Metastases

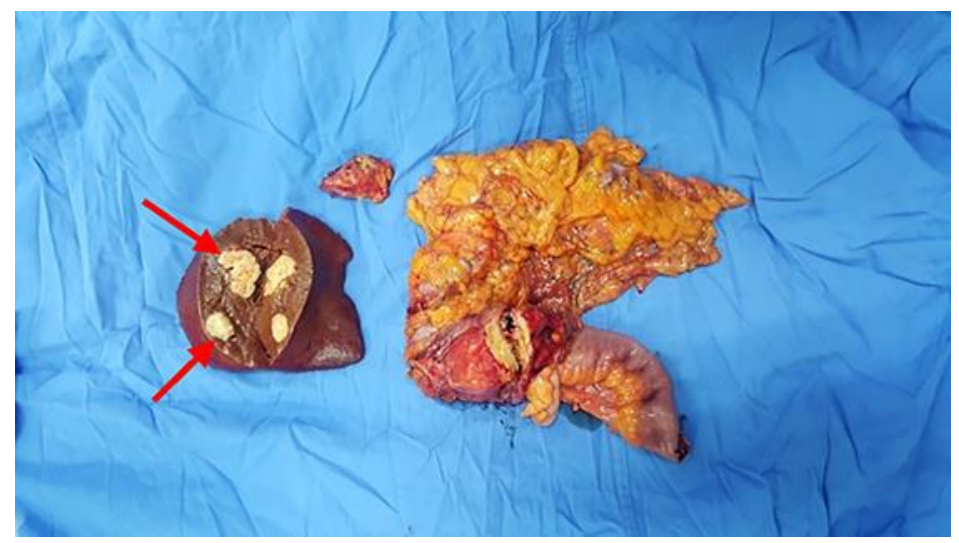

Fig. 3. Hepatic segments V and VI and the ascending and transverse colon. 